\title{
Triaxial Test Numerical Simulation Based on Duncan - Chang Model
}

\author{
Sun Dawei ${ }^{1, a}$ Chen Xiangwei, ${ }^{1, b}$ Wang Kangping ${ }^{1, c}$ LI Zhequn $^{1, d}$ \\ ${ }^{1}$ Three Gorges University Key Laboratory of Geological Hazard on Three Gorges Reservoir Area, \\ Ministry of Education, Hubei Yichang 443002 \\ adaweisun@126.com, b383029024@qq.com, cwkp@126.com, d786860368@qq.com
}

Keywords: finite elemen;Duncan-Chang constitutive model;rockfill dam;triaxial test

Abstract. Based on the secondary development platform of large-scale finite element software, the Fortran subroutine of Duncan - Chang EB constitutive model was compiled and embedded in software. Drainage consolidation shear triaxial test of Shuibuya dam materials was carried out. The triaxial experiment results at confining pressures $0.2 \mathrm{MPa}, 0.6 \mathrm{MPa}, 0.8 \mathrm{MPa}, 1.0 \mathrm{MPa}$ is compared with three dimensional finite element stress - strain results. It is proved that the classic Duncan -Chang model is suitable for $100 \mathrm{~m}$-high rockfill dam deformation simulation.

\section{Introduction}

Shuibuya dam is the world's highest concrete faced rockfill dam with the $233 \mathrm{~m}$ height. The rockfill material of the dam was taken into laboratory and triaxial test was carried out. The widely used Duncan-Chang EB model [1-2] was incorporated to the three dimensional software and finite element calculation was done to simulate the triaxial test process. The comparison between the experimental results and the numerical simulation results of the stress-strain relationship of the triaxial test of the Shuibuya rockfill is made. Different confining pressure conditions is considered.

The triaxial test results at confining pressures $0.2 \mathrm{MPa}, 0.6 \mathrm{MPa}, 0.8 \mathrm{MPa}, 1.0 \mathrm{MPa}$ is compared with three dimensional finite element stress - strain calculation results. It is proved that the classic Duncan -Chang model is suitable for 100m-high rockfill dam deformation and stress simulation.

\section{Software and constitutive model}

Software used in this paper is a powerful set of engineering simulation of finite element software, which solves the problem ranging from relatively simple linear analysis to complex nonlinear problems. It includes a rich library of libraries that can simulate any geometry. It also has a variety of material model libraries that can simulate the performance of typical engineering materials, including metals, rubbers, polymer materials, composites, reinforced concrete compressed super elastic foam materials, soil, rock and other geological materials. As a general simulation tool, it can not only solve a lot of structure stress and displacement problem, but also can simulate many other problems in the field of engineering, such as heat conduction, diffusion, acoustic analysis, thermoelectric coupling analysis of rock and soil mechanics such as fluid seepage and stress analysis coupling analysis and piezoelectric materials.

The software has two main solver modules. It also contains a comprehensive support solver graphical user interface, that is, human-computer interaction before and after processing module. It also provides a dedicated module for some special problems to solve. The software not only analyzes the complex mechanics of mechanical mechanics, but also can control very large and complex problems and simulate highly nonlinear problems. It can not only do a single part of the mechanical and multi-physics analysis, but also can do system-level analysis and research.

Its excellent analytical ability and simulation of complex system reliability make it widely used in national industry and research. It played a important role in a large number of high-tech product research. 


\section{Three dimensional mesh established}

According to the experiment sample, the finite element mesh of coarse-grained soil triaxial test is shown in Figure 1. The sample size is $600 \mathrm{~mm}$ height and 300 $\mathrm{mm}$ diameter, and the arrow around the sample represent confining pressure. The finite element simulation was carried out using the solid element. The mesh is composed of 3302 elements and 3383 nodes.

In order to make the finite calculation can simulate real experiment condition as much as possible as , below two measures were adopt:

Firstly, in the software "initial step", according to the test process in the model around the top and apply the same ambient pressure, the initial, self-equilibrium stress state is established, and at the bottom of the vertical displacement is constrained.

Secondly, in a subsequent step in the analysis, vertical displacement of the load is applied to the top of the sample and unbridled two horizontal directions at the top, while the constraint is applied at all three directions of sample bottom.

Thirdly, taking into account the axis symmetry character of model, the finite element mesh is radiation divided axis symmetry from the axis to the surrounding as shown in Figure 2.

Finally, the maximum displacement load is generally about $150 \mathrm{~mm}$, which represent axial strain $25 \%$. Therefore, $150 \mathrm{~mm}$ is chosen as the maximum axial displacement.

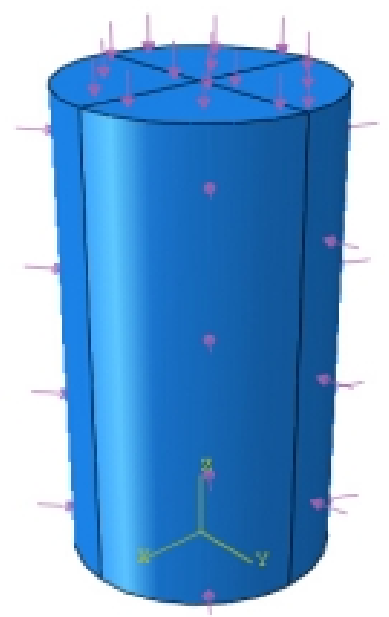

Fig. 1 tri- axial experiment sample model

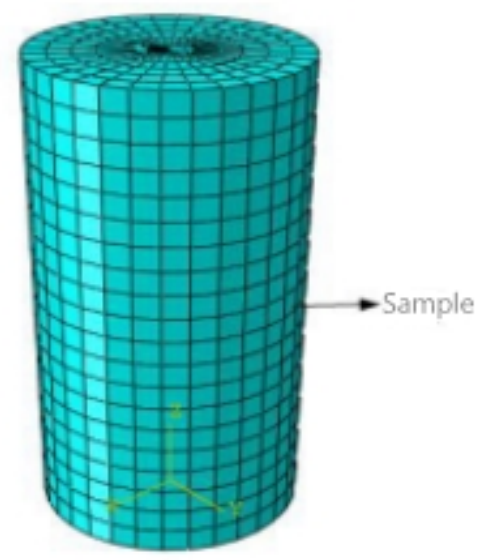

Fig. 2 Numerical simulation of the mesh 


\section{Duncan - Chang Constitutive Model}

Duncan [3] using the Mohr-Coulomb failure criterion, on the basis of empirical formula was proposed by Konder 1963 on the establishment of a soil nonlinear hyperbolic constitutive model shown is figure 3 and he proposed the namely Duncan - Chang model in 1970.

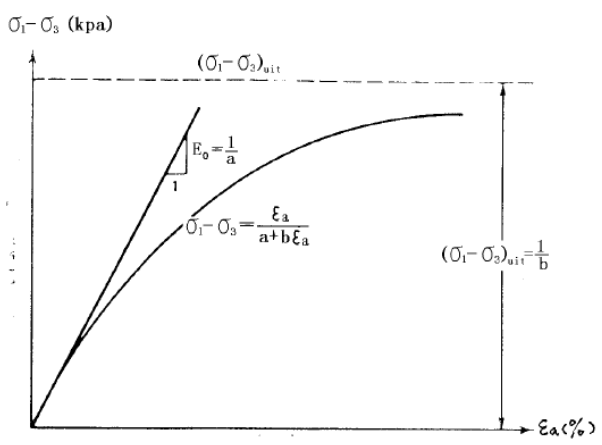

Fig. 3 (a) The relationship between $\sigma_{1}-\sigma_{3}$ and $\varepsilon_{a}$

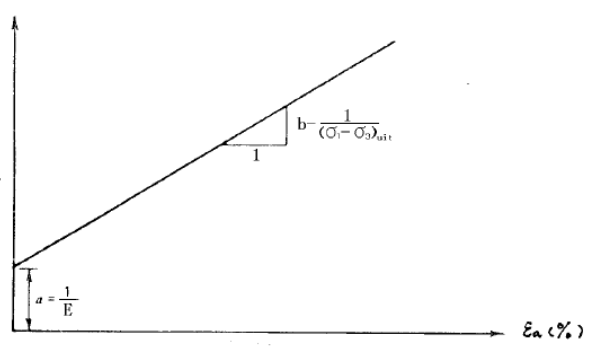

Fig. 3 (b) The relationship between $\varepsilon_{a} /\left(\sigma_{1}-\sigma_{3}\right)$ and $\varepsilon_{a}$

As shown in Figure 3. where is the $1 / a$ intercept slope of the line; $1 / b$ is the its asymptote line. As in the conventional triaxial compression test, since the tangential modulus is:

$$
E_{t}=\frac{d\left(\sigma_{1}-\sigma_{3}\right)}{\varepsilon_{1}}=\frac{a}{\left(a+b \varepsilon_{1}\right)^{2}}
$$

At the beginning of the triaxial experiment, $\varepsilon_{1}=0, E_{t}=E_{i}$, then

$$
E_{i}=\frac{1}{a}
$$

This indicates that a represents the reciprocal of the initial deformation modulus in this test. When $\varepsilon_{1} \rightarrow \infty$, then

$$
\left(\sigma_{1}-\sigma_{3}\right)_{u l t}=\frac{1}{b}
$$

It means that $1 / b$ represents the reciprocal of the limit deviation stress $\left(\sigma_{1}-\sigma_{3}\right)_{u l t}$ corresponding to the asymptote of the hyperbola.

In soil samples, if the stress-strain curve is similar to a hyperbolic relationship, the strength of the soil $\left(\sigma_{1}-\sigma_{3}\right)_{f}$ is often determined according to a certain strain value (eg, $\left.\varepsilon_{1}=15 \%\right)$. It is not possible to make $\varepsilon_{1}$ infinite in the test $\left(\sigma_{1}-\sigma_{3}\right)_{u l t}$; for the case of a peak, take $\left(\sigma_{1}-\sigma_{3}\right)_{f}=\left(\sigma_{1}-\sigma_{3}\right)_{u}$.

$$
\text { So }\left(\sigma_{1}-\sigma_{3}\right)_{f}<\left(\sigma_{1}-\sigma_{3}\right)_{u l t} \text {. }
$$


Define the damage stress ratio $\mathrm{R}_{\mathrm{f}}$ for:

$$
R_{f}=\frac{\left(\sigma_{1}-\sigma_{3}\right)_{f}}{\left(\sigma_{1}-\sigma_{3}\right)_{u l t}}
$$

bring equation (4.2) into the (4.3), get:

$$
b=\frac{1}{\left(\sigma_{1}-\sigma_{3}\right)_{u l t}}=\frac{R_{f}}{\left(\sigma_{1}-\sigma_{3}\right)_{f}}
$$

Finally substitute a and $\mathrm{b}$ into $\quad \sigma_{1}-\sigma_{3}=\frac{\varepsilon_{1}}{a+b \varepsilon_{1}}$

$$
\begin{gathered}
\left(\sigma_{1}-\sigma_{3}\right)=\frac{\varepsilon_{1}}{\frac{1}{E_{i}}+\frac{\varepsilon_{1} R_{f}}{\left(\sigma_{1}-\sigma_{3}\right)_{f}}} \\
E_{i}=K P_{a}\left(\frac{\sigma_{3}}{P_{a}}\right)^{n}
\end{gathered}
$$

Where $\sigma_{1}$ and $\sigma_{3}$ are the maximum and minimum principal stresses, $\varepsilon_{1}$ is the axial strain, $P_{a}$ is the atmospheric pressure; $K 、 n$ is the modulus coefficient and modulus index, are dimensionless constant, determined by the experiment.

The failure strength of $\left(\sigma_{1}-\sigma_{3}\right)_{f}$ can be determined by Mohr-Coulomb failure criterion:

$$
\left(\sigma_{1}-\sigma_{3}\right)_{f}=\frac{2 c \cos \varphi_{p}+2 \sigma_{3} \sin \varphi_{p}}{1-\sin \varphi_{p}}
$$

$\varphi_{p}$ is the peak friction angle.

$$
E_{t}=\frac{d\left(\sigma_{1}-\sigma_{3}\right)}{d \varepsilon_{1}}=\frac{d \sigma_{1}}{d \varepsilon_{1}}=\frac{1}{E_{i}}\left[\frac{1}{\frac{1}{E_{i}}+\frac{R_{f}}{\left(\sigma_{1}-\sigma_{3}\right)_{f}} \varepsilon_{1}}\right] 2
$$

The bulk modulus ratio of the Duncan-Chang E-B model is:

$$
B_{t}=k_{b} P_{a}\left(\frac{\sigma_{3}}{P_{a}}\right)^{m}
$$

Duncan E-B model is relatively simple in mathematics, the concept is clear and simple. The test parameters listed in table 1 are only eight, each has a certain physical and geometric significance, and can be obtained by conventional triaxial test.

Table 1 Material parameters of coarse - grained soil

\begin{tabular}{|c|c|c|c|c|c|c|c|}
\hline $\mathrm{K}$ & $\mathrm{n}$ & $\mathrm{Rf}$ & $\mathrm{c}\left(\mathrm{N} / \mathrm{m}^{2}\right)$ & $\Phi$ & $\mathrm{Kb}$ & $\mathrm{m}$ & $\mathrm{Kur}$ \\
\hline 1180 & 0.50 & 0.89 & 23000 & 30.1 & 487 & 0.1 & 2360 \\
\hline
\end{tabular}

\section{Comparison of simulation results with triaxial test results}

The following figure 4-7 are of Shuibuya rockfill materials in $0.2 \mathrm{MPa}, 0.6 \mathrm{MPa}, 0.8 \mathrm{MPa}, 1.0 \mathrm{MPa}$ consolidation confining pressure compared the result between experimental results on stress-strain relationship of consolidated drained triaxial test data and numerical simulation results[4-6].

In figure 4 the confining pressure is $0.2 \mathrm{MPa}$, since the confining pressure is small, the experimental curves show obvious dilatation characteristics. 
In figure 5 the confining pressure is $0.6 \mathrm{MPa}$, the simulated stress-strain curve is close to the experimental curve. With the increase of confining pressure, the internal particles of the sample will be partially broken, because the limitations of the Duncan E-B model can not reflect the impact of particle crushing, making the simulation results

In figure 6 the maximum difference between the calculated value and measured data of about $0.5 \mathrm{MPa}$.

In figure 7, the maximum difference between the simulation result and the experimental data is about $0.8 \mathrm{MPa}$.

All the stress - strain curve relationship shows the non - linearity of the main rockfill material, and the simulation curve is consistent with the experimental curve.

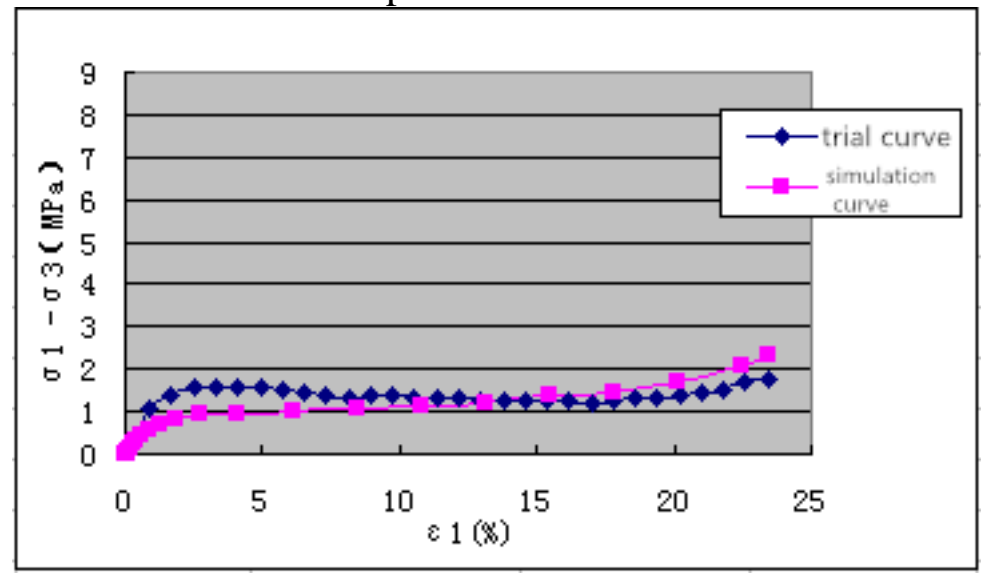

Fig. 4 Confining pressure is $0.2 \mathrm{MPa}$

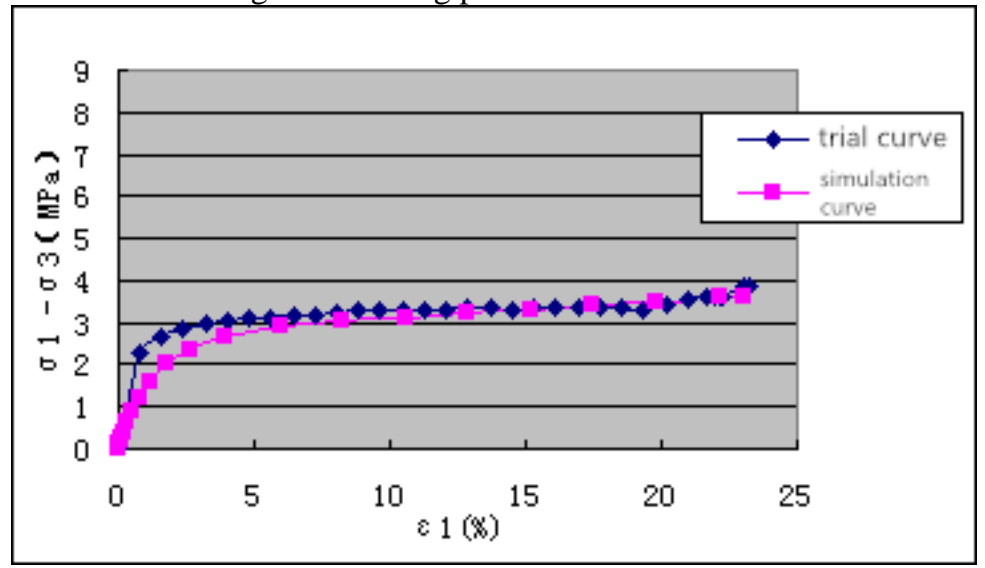

Fig. 5 Confining pressure is $0.6 \mathrm{MPa}$

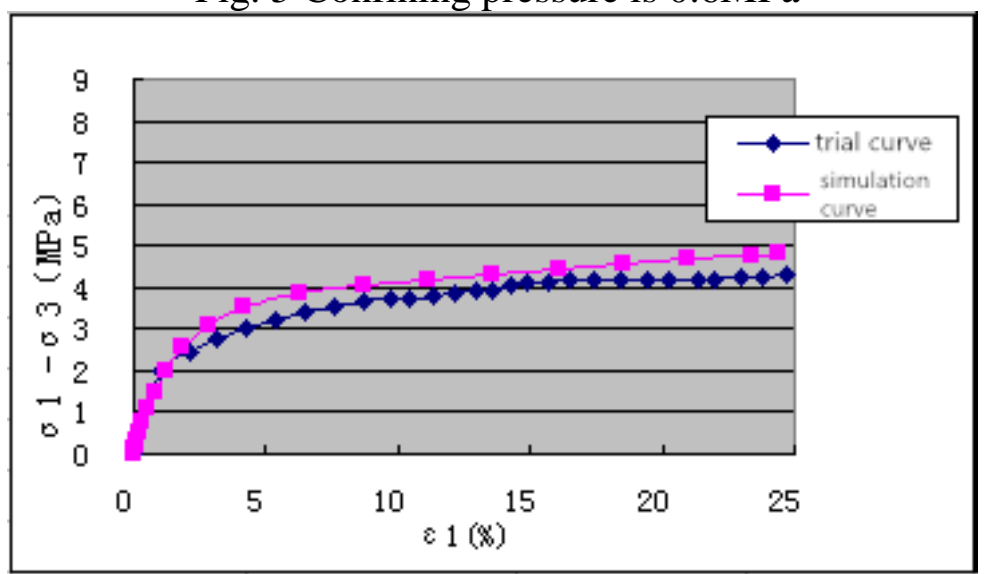

Fig. 6 Confining pressure is $0.8 \mathrm{MPa}$ 


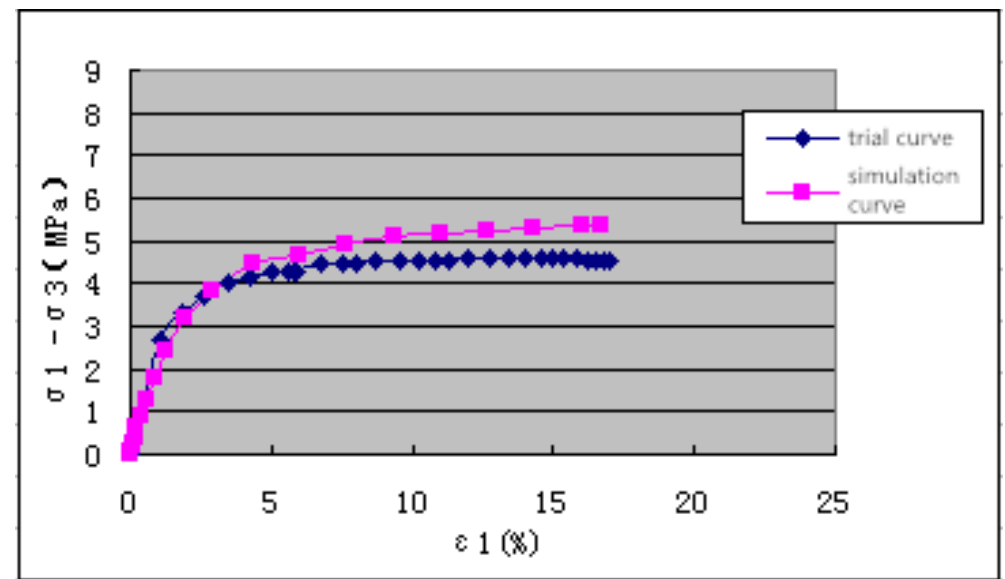

Fig. 7 Confining pressure is $1.0 \mathrm{MPa}$

Figure 8-11 shows the axial strain profile of the longitudinal section under different confining pressures. It can be seen from the figure, the maximum strain occurs in middle of the sample axial, while minimum at the upper and lower position. because the upper and lower contact constraints of test sample can not be avoid, the final specimen after unloading will become a drum shape which is shown in the figures.

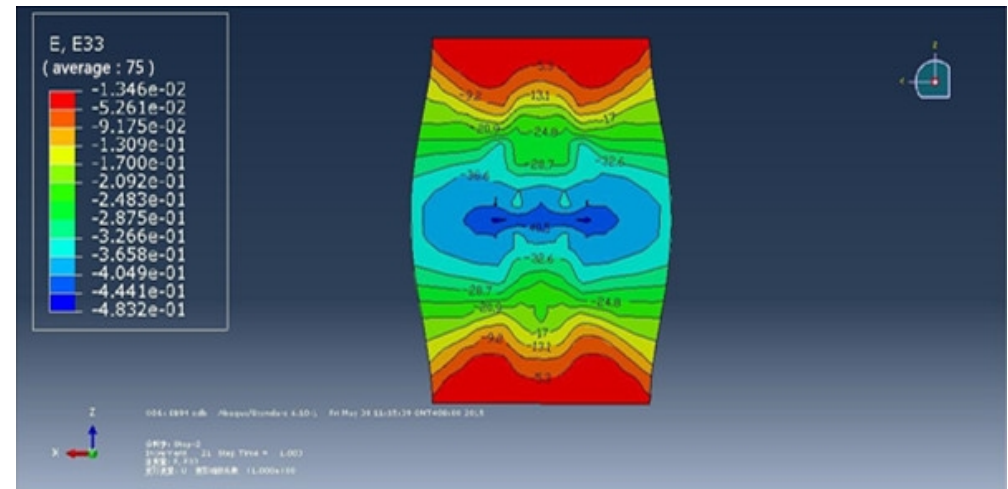

Fig. 8 Strain at confining pressure $0.2 \mathrm{MPa}$

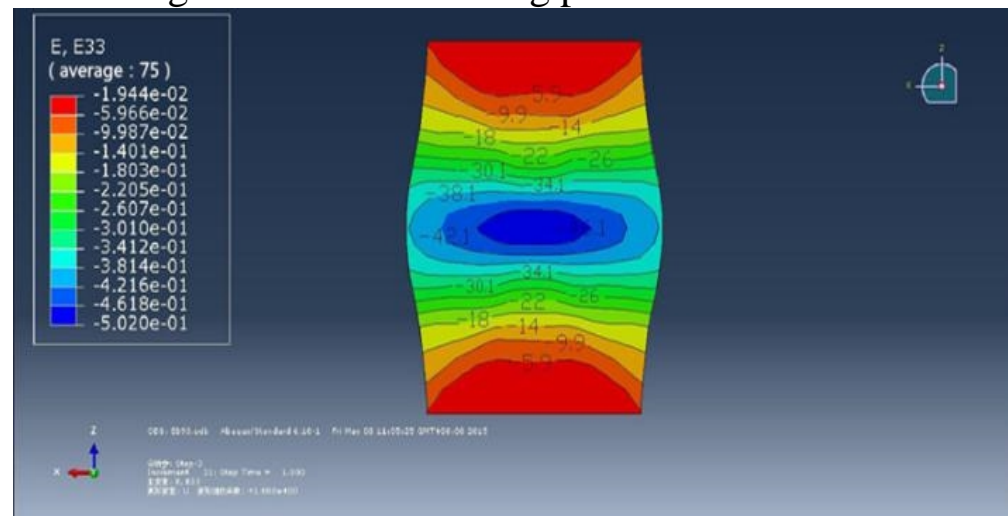

Fig. 9 Strain at confining pressure $0.6 \mathrm{MPa}$

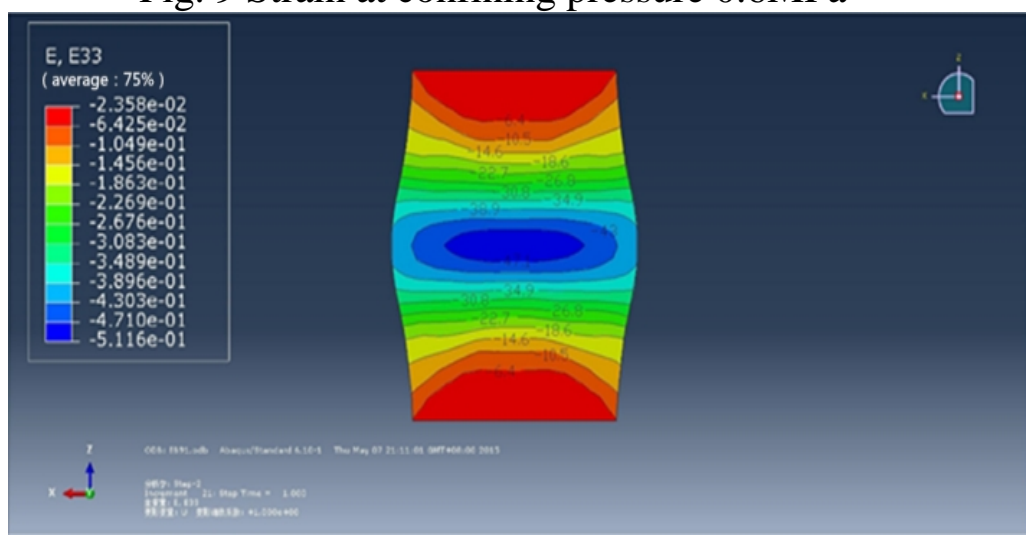

Fig. 10 Strain at confining pressure $0.8 \mathrm{MPa}$ 


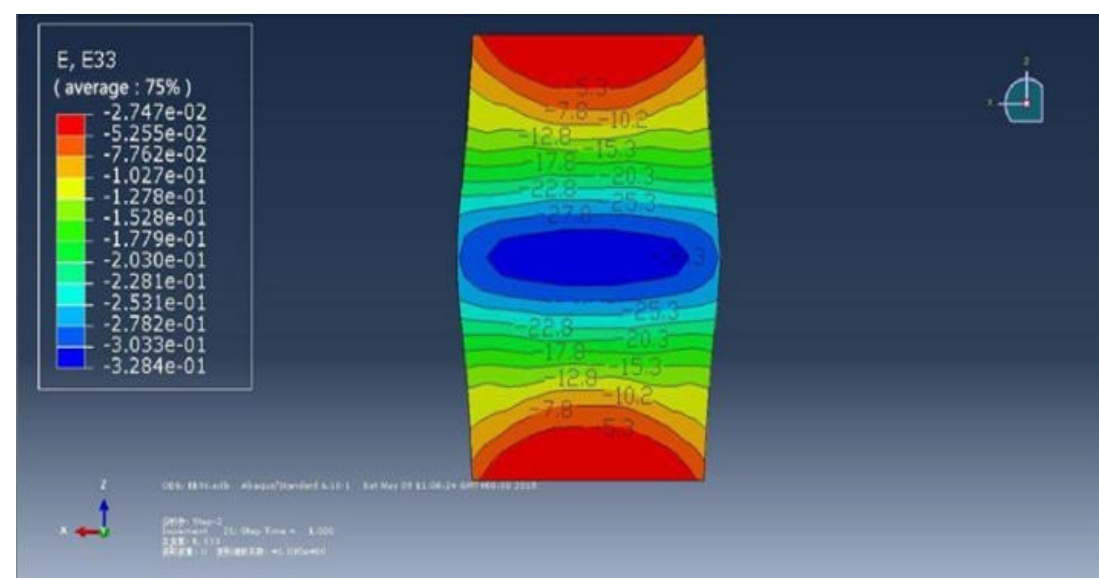

Fig. 11 Strain at confining pressure is $1.0 \mathrm{MPa}$

\section{Summary}

Based on the secondary development platform of large-scale finite element software, the Duncan E-B constitutive model Fortran subroutine was compiled and embedded in the software. Shuibuya main rockfill materials consolidated drained triaxial test is done and then the numerical simulation is performed. Following conclusions is drawn:

(1) The numerical simulation can reflect the qualitative Shuibuya main rockfill materials under $100 \mathrm{~m}$ height confining pressure. It made a good foundation for further study of coarse grained soil under high confining pressure under the macroscopic and microcosmic;

(2) The test axis strain reached about $24 \%$, while the demand of regulation is only $15 \%$. The test data is precious, it will do benefit for the subsequent constitutive model research;

(3) axial strain contour shows the stress change process is consistent with the actual test results, and the simulation results is reasonable;

(4) Compared with the stress-strain curves under different confining pressures, the Duncan E-B model has better fitting effect under low confining pressure below 1.0MPa. Under high confining pressure such as $1.5 \mathrm{MPa}$ and 3.0MPa, more particles broken will happen and Duncan E-B model fitting effect is not ideal. Thus, we can see that the limitations of the Duncan E-B model are that it could not effectively reflect the effect of particle broken under high confining pressure.

\section{Acknowledgements}

This work was financially supported by National Natural Science Foundation of China（51179097）.

\section{References}

[1] YAN Deshun, WANG Baotian, WANF Yuntao. Duncan - Chang model under different stress path modulus formula [J]. Journal of geotechnical engineering. 2007 (9)

[2] XU Han, CHENG Zhanlin, TAI Pei, PAN Jia-jun, HUANG Bin. Coarse grained soil of centrifugal model test and numerical simulation [J].The basic theory and experimental research. 2015(5)

[3] Duncan JM, Chang CY. Nonlinear analysis of stress and strain in soils. Journal of the Soil Mechanics and Foundations Division,ASCE. 1970

[4] XU Ping, SHAO Shengjun, ZHANG Zhe, LUO Aizhong. True triaxial stress under the condition of fixed Duncan - Chang model experimental study.[J].The basic theory and experimental research. 2013(12) 
[5] ZHANG Ming, DAI Lei. Based on the Duncan - Chang E - B model research and application of the slope stability of strength subtraction.[J].Scientific research. 2014(6)

[6] Mingqiang Wang, Jun Yang. Three Dimensional Implementation of HISS Model in ABAQUS [Z].The Second International Symposium on Constitutive Modeling of Geomateria 